\title{
Characteristics of juvenile onset systemic sclerosis patients in an adult single centre cohort. Does this patient population present a survival bias? I Foeldvari*1, S Nihtanova ${ }^{2}$, A Wierk ${ }^{1}$ and CP Denton ${ }^{2}$
}

\author{
Address: ${ }^{1}$ Hamburger Zentrum für Kinder- und Jugendrheumatologie, Hamburg, Germany and ${ }^{2}$ Centre for Rheumatology, Royal Free Hospital \\ London, London, UK \\ * Corresponding author
}

\author{
from 15th Paediatric Rheumatology European Society (PreS) Congress \\ London, UK. 14-17 September 2008 \\ Published: 15 September 2008 \\ Pediatric Rheumatology 2008, 6(Suppl I):P224 doi:10.I 186/I546-0096-6-SI-P224
}

This abstract is available from: http://www.ped-rheum.com/content/6/SI/P224

(c) 2008 Foeldvari et al; licensee BioMed Central Ltd.

Juvenile systemic sclerosis (jSSc) is a rare autoimmune disease in childhood. Currently data regarding long-term outcome of jSSc is scare. We evaluated a large single centre cohort to learn more about the characteristics of jSSc patients in an adult cohort.

From more than 1800 cases of SSc, 46 adults with jSSc were identified. The median age of onset was 13.06 years (range 5 to 16). 35 (76\%) were female. Median age at last visit was 32.67 years (range 16 to 71 ). The median disease duration was 21.15 years (range 3 to 58 ). $39 \%$ of the patients had a diffuse and $61 \%$ a limited subtype of SSc. $20(43.5 \%)$ of the 46 patients showed overlap features of other connective tissue diseases. Three $(6.5 \%)$ patients had anticentromere antibodies. 12 (26\%) patients were anti-Scl 70 positive. The most common organ involvements were oesophageal in 33 patients $(72 \%)$, pulmonary fibrosis in 22 patients (47\%), bowel involvement in 9 patients $(20 \%)$ and pulmonary hypertension in 7 patients $(15 \%)$. Interestingly 7 patients $(15 \%)$ did not have any major organ involvement beside skin and vascular involvement. The survival of the 46 patients after 15, 20 and 25 years was $97 \%, 93 \%$ and $83 \%$. The mean disease duration of these patients was 28.86 years (range 17 to 47).

This patient population has similar organ involvement and disease subtype characteristics as expected from an adult SSc cohort. It is likely the study cohort of patients reflect a survival bias. The antinuclear antibody pattern contrasts markedly with adult SSc. 